\title{
The potential protective role of grape seed proanthocyanidin extract against the mixture of carboplatin and thalidomide -induced hepatotoxicity and cardiotoxicity in male rats
}

\author{
Mokhtar I Yousef ${ }^{1}$, Moustafa AFH Mahdy ${ }^{1}$ and Heba M Abdou ${ }^{2 \star}$ \\ ${ }^{1}$ Department of Environmental Studies, Institute of Graduate Studies and Research, Alexandria University, Egypt \\ ${ }^{2}$ Zoology Department, Faculty of Science, Alexandria University, Egypt
}

\begin{abstract}
Thalidomide is used experimentally to treat various cancers, also carboplatin is a chemotherapy drug used against some forms of cancer. Grape Seed Proanthocyanidin Extract (GSPE) has an enormously beneficial role in overcoming the adverse effects of chemotherapeutic agents due to its excellent antioxidant properties. Animals were divided into four groups as follows: The first group was used as control, the second group were treated orally for 28 consecutive days with GSPE ( $200 \mathrm{mg} /$ $\mathrm{kg} \mathrm{BW})$, the third group were treated intraperitoneally (i.p) with thalidomide $(60 \mathrm{mg} / \mathrm{kg} \mathrm{BW})$ for 14 consecutive days then followed by carboplatin (196 mg/kg BW) for another 14 days and the animals of the fourth group were treated with the combination of GSPE (200 mg/kg BW) and thalidomide ( $60 \mathrm{mg} / \mathrm{kg}$ BW) for 14-day and then followed by GSPE (200 mg/kg BW) and carboplatin (196 mg/kg BW) for other 14-day. Inflammatory cytokines, P53, oxidative stress markers, biochemical parameters, and histological analysis measured. Carboplatin and thalidomide caused oxidative stress via the elevation in free radicals and nitric oxide and the reduction in the antioxidant enzymes and glutathione in liver and heart. Tumor suppressor gene P53, tumor necrosis factor- $\alpha$, and interleukin- 6 were significantly increased in liver and heart. Thalidomide and carboplatin caused biochemical and histological changes in the liver and heart. Grape seed proanthocyanidin extract reduced carboplatin and thalidomide -induced liver and heart injury throughout its potent antioxidant activity. In conclusion, carboplatin and thalidomide caused hepatotoxicity and cardiotoxicity and grape seed proanthocyanidin extract showed hepatic and cardiac protective effects due to its antioxidant and anti-inflammatory potentials.
\end{abstract}

\section{Introduction}

Thalidomide was primary used as a sedative, but it was withdrawn from the market after its teratogenic effects [1]. In spite of its teratogenicity, thalidomide possesses immune-modulatory, antiinflammatory and anti-angiogenic properties that are potentially useful in several diseases [2]. Currently, thalidomide is used experimentally to treat various cancers, dermatological, neurological and inflammatory diseases. The immunomodulatory activities, together with the antiangiogenic, anti-proliferative and pro-apoptotic properties, are believed to mediate anti-tumor responses as observed in multiple myeloma and some solid tumors. Thalidomide and its analogs modulate the immune system in different ways [3]. Lenalidomide has shown potential in treating the bone marrow disorders multiple myeloma and myelodysplastic syndrome and is presently in Phase II and III trials [4].

Carboplatin is used against some forms of cancer, mainly ovarian carcinoma, lung, as well as endometrial, esophageal, bladder, breast and cervical; central nervous system or germ cell tumors; osteogenic sarcoma and as preparation for a stem cell or bone marrow transplant [5]. The myelosuppressive effect is the main obstruction of carboplatin. This causes the blood cell and platelet output of bone marrow in the body to decline quite massively [6].

Cancer chemotherapy induces lipid peroxidation, generates numerous electrophilic aldehydes and free radicals which can attack many cellular targets. These products of oxidative stress can delay cell cycle progression of cancer cells and cause cell cycle checkpoint arrest that may intervene with the potency of anticancer drugs to kill cancer cells [7]. The aldehydes may also inhibit drug-induced apoptosis by obstruction death receptors and suppressing caspase activity. They added, grape seed proanthocyanidin may be reduce the generation of oxidative stress-stimulated aldehydes.

Antioxidant supplements are used during treatment with chemotherapy attributable to their role in the efficacy of the chemotherapy, as well as diminish toxic side effects, allowing patients to tolerate chemotherapy for the full course of treatment and at higher doses [8]. In addition, antioxidants have several mechanisms of action depending on their use, which noted to have the potential to serve as oxidant molecules themselves [9]. The supplements have a wide range in their antioxidant mechanisms from free radical scavengers that act by the preservation of cellular defense mechanisms or could be worked as reducers [10]. Additionally, aside from their antioxidant activities, these agents may manipulate the pharmacokinetics or pharmacodynamics of chemotherapeutic agents [11].

The beneficial role of Grape Seed Proanthocyanidin Extract (GSPE) against adverse effects of chemotherapeutic agents probably owing to its excellent antioxidant properties and high nutritional values [12].

*Correspondence to: Heba Mohamed Abdou, Department of Zoology, Faculty of Science, Alexandria University, Egypt, Tel:+203-3921595; E-mail: dr.heba abdou3000@yahoo.com

Key words: thalidomide, carboplatin, grape seed proanthocyanidin, hepatic toxicity, cardiotoxicity, cytokines

Received: November 02, 2019; Accepted: November 15, 2019; Published: November 21, 2019 
Yousef MI (2019) The potential protective role of grape seed proanthocyanidin extract against the mixture of carboplatin and thalidomide -induced hepatotoxicity and cardiotoxicity in male rats

Also, grape seed proanthocyanidin extract (GSPE) caused enzymatic enhancement, may be due to its antioxidative phytochemicals as flavonoids [7].

Therefore, the present study was carried out to investigate the possible protective role of grape seed proanthocyanidin extract against the mixture of thalidomide and carboplatin-induced hepatic and cardiac toxicity in male rats.

\section{Materials and methods}

\section{Tested compounds and doses}

Thalidomide $\left(\mathrm{C}_{13} \mathrm{H}_{10} \mathrm{~N}_{2} \mathrm{O}_{4}\right)$ was purchased from Sigma Chemical Company (St. Louis, MO, USA). Carboplatin $\left(\mathrm{C}_{6} \mathrm{H}_{14} \mathrm{~N}_{2} \mathrm{O}_{4} \mathrm{Pt}\right)$ obtained from Vita for NV/SA, additives and pharmaceutical, Germany (www. vitafor.com). A dried, powdered grape seed proanthocyanidin extract (GSPE) was obtained from Pharco Pharmaceuticals Company, Alexandria, Egypt. The dose of thalidomide was $60 \mathrm{mg} / \mathrm{kg}$ according to the study of Ilona et al. [13]. The dose of carboplatin was $196 \mathrm{mg} / \mathrm{kg}$ according to Husain et al. [14]. The dose of grape seed proanthocyanidin extract (GSPE) was $200 \mathrm{mg} / \mathrm{kg} \mathrm{BW}$ according to Yousef et al. [7].

\section{Animals and experimental groups}

Forty Wistar male rats weighing 160-180g were used in the current study. They were obtained from the Faculty of Medicine, Alexandria University, Alexandria, Egypt. Animals were housed in a stainlesssteel wire cages, kept on basal diet and given feed and water ad libitum. Rats fed pellets which consisted of $30 \%$ berseem (Trifolium alexandrinum) hay, $25 \%$ yellow corn, $26.2 \%$ wheat bran, $14 \%$ soybean meal, $3 \%$ molasses, $1 \% \mathrm{CaCl}_{2}, 0.4 \% \mathrm{NaCl}, 0.3 \%$ mixture of minerals and vitamins, and $0.1 \%$ methionine. The vitamin and mineral premix per $\mathrm{kg}$ contained the following IU/gm for vitamins or minerals: Vit. A-4000,000, Vit D3-5000, 000, vit E-16.7 g, K-0.67 g, vit B1-0.67 g, vit B2-2 g, B6-0.67 g, B12-0.004 g, B5-16.7 g, Pantothenic acid-6.67 g, Biotin-0.07 g, Folic acid-1.67 g, Choline chloride- 400 g, Zn-23.3 g, Mn10 g, Fe-25 g, Cu-1.67 g, I-0.25 g, Se-0.033 g, and Mg-133.4 g (Rabbit premix produced by Holland Feed Inter. Co.). The chemical analysis of the pellets [15] showed that they contained $15.8 \%$ crude protein, 11.3 $\%$ crude fiber, $3.7 \%$ ether extract, $7.2 \%$ ash, $92.9 \%$ organic matter and $62.4 \%$ nitrogen-free extract \% as dray matter (DM) basis". They were maintained in a controlled atmosphere, a temperature of $25 \pm$ $5{ }^{\circ} \mathrm{C}$ and $50-70 \%$ humidity. After two weeks of acclimation, animals were divided into four equal groups as follows: the animals of the first group were used as control, the animals of the second group were treated orally for 28 consecutive days with GSPE ( $200 \mathrm{mg} / \mathrm{kg} \mathrm{BW})$; the proper doses of grape seed proanthocyanidin extract were placed into a syringe that was inserted orally with the help of plastic tube directly into the oropharyngeal region. The animals of the third group were treated intraperitoneally (i.p) with thalidomide $(60 \mathrm{mg} / \mathrm{kg} \mathrm{BW})$ for 14 consecutive days then followed by carboplatin $(196 \mathrm{mg} / \mathrm{kg} \mathrm{BW})$ for another 14 days and the animals of the fourth group were treated with the combination of GSPE $(200 \mathrm{mg} / \mathrm{kg} \mathrm{BW})$ and thalidomide $(60 \mathrm{mg} /$ $\mathrm{kg} \mathrm{BW})$ for 14-day and then followed by GSPE (200 mg/kg BW) and carboplatin $(196 \mathrm{mg} / \mathrm{kg} \mathrm{BW})$ for other 14-day.

\section{Blood samples collection and tissue preparations}

At the end of the $28^{\text {th }}$ day of the experimental period, all animals of each group were sacrificed. Blood samples were collected from anesthetized rats in test tubes containing heparin as an anticoagulant and placed immediately on ice. The collected blood was centrifuged at $860 \times g$ for $20 \mathrm{~min}$ for the separation of plasma. The plasma was kept at $-80^{\circ} \mathrm{C}$ until analyses of the examined parameters. Liver and heart were immediately removed, washed using chilled saline solution and removed the adhering fat and connective tissues. Liver and heart were divided into two parts; one part was immersed immediately in formalin for histological analysis, another part was minced and homogenized $(10 \%, w / v)$, separately, in ice-cold sucrose buffer $(0.25 \mathrm{M})$ in a PotterElvehjem type homogenizer, the homogenates were centrifuged at $10,000 \times g$ for $20 \mathrm{~min}$ at $4{ }^{\circ} \mathrm{C}$, to pellet the cell debris and the supernatant was collected and stored at $-80^{\circ} \mathrm{C}$ for the determination of the rest of parameters.

\section{ELISA measurements}

Tumor suppressor gene p53, tumor necrosis factor- alpha (TNF- $\alpha$ ) and interleukin-6 (IL-6) were inspected by using Enzyme-Linked Immunosorbent Assay (ELISA) kits in the liver and heart tissue homogenates [16-18].

\section{Markers of oxidative stress}

Thiobarbituric Acid-Reactive Substances (TBARS) were measured in liver and heart homogenates at $532 \mathrm{~nm}$ by using 2 -thiobarbituric acid (2,6-dihydroxypyrimidine-2-thiol; TBA). Total Antioxidant Capacity (TAC) and the level of Nitric Oxide (NO) were assayed in liver and heart homogenates. Superoxide Dismutase (SOD) was determined at $480 \mathrm{~nm}$. Glutathione Peroxidase (GPX) activity was established in liver and heart homogenates. The activity of GST was measured in tissue homogenates at $310 \mathrm{~nm}$ using UV-Double Beam Spectrophotometer. The CAT activity in tissue homogenates was measured at $240 \mathrm{~nm}$. Reduced glutathione content was determined at $412 \mathrm{~nm}$. All the above assays were determined according to the manual instruction of Biodiagnostic Kit, Egypt.

\section{Biochemical parameters}

Heart paraoxonase (PON1) activity, plasma total protein, and albumin were measured. The activities of Plasma Aspartate Transaminase (AST), Alanine Transaminase (ALT), Alkaline Phosphatase (ALP) And Acid Phosphatase (ACP) were measured by kits from Biosystems S.A (Costa Brava 30, Barcelona, Spain).

\section{Histological section preparation of liver and heart}

Liver and heart specimens were obtained from rats and immediately fixed in $10 \%$ formalin and then treated with a conventional grade of alcohol and xylol, embedded in paraffin and sectioned at 4-6 $\mu \mathrm{m}$ thickness. The sections were stained with Haematoxylin and Eosin (H\&E) stain for studying the histopathological changes [19].

\section{Statistical analysis}

Results are reported as means \pm SE. Statistical analysis for all studied parameters was performed using the General Linear Model (GLM) produced by the Statistical Analysis Systems Institute [20] Duncan's New Multiple Range Test was used to test the significance of the differences between means [21]. Values of $p<0.05$ were considered statistically significant.

\section{Results}

Effect of grape seed proanthocyanidin extract, thalidomide, carboplatin and their combination on tumor suppressor p53, tumor necrosis factor- $\alpha$, interleukin- 6

Administration of thalidomide followed by carboplatin caused significant $(p>0.05)$ increase in liver and heart p53, TNF- $\alpha$ and IL-6 
Yousef MI (2019) The potential protective role of grape seed proanthocyanidin extract against the mixture of carboplatin and thalidomide -induced hepatotoxicity and cardiotoxicity in male rats

compared to the control group (Table 1). The combination of GSPE with thalidomide and carboplatin significant $(p>0.05)$ decrease in liver and heart p53, TNF- $\alpha$ and IL- 6 compared to a group of thalidomide and carboplatin. GSPE alone significantly $(p>0.05)$ decreased P53, TNF- $\alpha$ and IL- 6 in the liver and insignificantly $(p<0.05)$ increased in P53, significantly $(p>0.05)$ increased TNF- $\alpha$ and IL-6 in the heart compared to the control group.

Effect of grape seed proanthocyanidin extract, thalidomide, carboplatin and their combination of free radicals and antioxidant enzymes

Thalidomide followed by carboplatin significantly $(p>0.05)$ increased in the liver and heart TBARS and $\mathrm{NO}$ also significantly $(p>0.05)$ decreased in the liver and heart GSH, TAC and antioxidant enzymes (SOD, CAT, GPx, and GST) as compared to control group (Tables 2 and 3). However, the presence of GSPE with thalidomide and carboplatin significantly $(p>0.05)$ decreased in TBARS and NO as well as significantly $(p>0.05)$ increased in GSH, TAC and antioxidant enzymes (SOD, CAT, GPx, and GST) in liver and heart compared to thalidomide and carboplatin group. On the other hand, treatment with GSPE alone significant $(p>0.05)$ decrease in the levels of TBARS and NO and significant $(p>0.05)$ increase GSH and antioxidant enzymes (SOD, CAT, GPx, and GST) in the liver and heart compared to the control group. However, TAC insignificantly $(p>0.05)$ increased in the liver and heart.

\section{Effect of grape seed proanthocyanidin extract, thalidomide, carboplatin and their combination on heart paroxanase (PON1) and plasma biochemical parameters}

The present data showed that treatment with thalidomide followed by carboplatin significantly $(p>0.05)$ decreased PON1 in the heart compared to the control group (Table 4). The presence of GSPE with thalidomide and carboplatin significantly $(p>0.05)$ increased the level of PON1 in the heart compared thalidomide and carboplatin group.

Table 1. Liver and heart levels of tumor suppressor p53 (p53), tumor necrosis factor- $\alpha$ (TNF- $\alpha$ ) and interliukin-6 (IL-6) of male rats treated with grape seed proanthocyanidin extract (GSPE), thalidomide, carboplatin and their combination (Mean values $\pm \mathrm{SE}$ )

\begin{tabular}{|c|c|c|c|c|}
\hline \multirow{2}{*}{ Parameter } & \multicolumn{4}{|c|}{ Experimental groups } \\
\hline & Control & GSPE & Thalidomide + Carboplatin & Thalidomide + Carboplatin + GSPE \\
\hline $\begin{array}{c}\text { Liver } \\
\text { P53 (pg /mg protein) }\end{array}$ & $11.3 \pm 0.08^{c}$ & $10.5 \pm 0.10^{\mathrm{d}}$ & $18.4 \pm 0.07^{\mathrm{a}}$ & $15.7 \pm 0.10^{\mathrm{b}}$ \\
\hline TNF- $\alpha$ (pg/g tissue) & $4089 \pm 95^{c}$ & $3100 \pm 48^{\mathrm{d}}$ & $20849 \pm 35^{\mathrm{a}}$ & $11450 \pm 41^{\mathrm{b}}$ \\
\hline IL-6 (pg/g tissue) & $4095 \pm 174^{c}$ & $2606 \pm 23^{d}$ & $11236 \pm 114^{\mathrm{a}}$ & $9936 \pm 45^{b}$ \\
\hline $\begin{array}{c}\text { Heart } \\
\text { P53 (pg /mg protein) }\end{array}$ & $8.1 \pm 0.07^{\mathrm{c}}$ & $8.7 \pm 0.36^{\mathrm{c}}$ & $16.4 \pm 0.09^{\mathrm{a}}$ & $11.8 \pm 0.17^{\mathrm{b}}$ \\
\hline TNF- $\alpha$ (pg/g tissue) & $2643 \pm 247^{d}$ & $2875 \pm 203^{c}$ & $11468 \pm 219^{a}$ & $7177 \pm 266^{\mathrm{b}}$ \\
\hline IL-6 (pg/g tissue) & $10314 \pm 66^{\mathrm{d}}$ & $11346 \pm 95^{\mathrm{c}}$ & $14428 \pm 62^{\mathrm{a}}$ & $11975 \pm 54^{\mathrm{b}}$ \\
\hline
\end{tabular}

Mean values within a row not sharing a common superscript letter (a, b, c, d) were significantly different, $p<0.05$.

Table 2. Liver free radicals, nitric oxide and antioxidant enzymes of male rats treated with grape seed proanthocyanidin extract (GSPE), thalidomide, carboplatin and their combination (Mean values $\pm \mathrm{SE}$ )

\begin{tabular}{|c|c|c|c|c|}
\hline \multirow{2}{*}{ Parameter } & \multicolumn{4}{|c|}{ Experimental groups } \\
\hline & Control & GSPE & Thalidomide + Carboplatin & Thalidomide + Carboplatin + GSPE \\
\hline TBARS & $21.8 \pm 1.85 \mathrm{c}$ & $19.4 \pm 1.47 \mathrm{~d}$ & $32 \pm 2.9 \mathrm{a}$ & $27.5 \pm 2.52 \mathrm{~b}$ \\
\hline NO & $0.47 \pm 0.04 b$ & $0.36 \pm 0.06 \mathrm{c}$ & $0.71 \pm 0.04 \mathrm{a}$ & $0.32 \pm 0.02 \mathrm{~d}$ \\
\hline GSH & $6.1 \pm 0.16 b$ & $7.1 \pm 0.23 \mathrm{a}$ & $4.6 \pm 0.22 \mathrm{~d}$ & $5.2 \pm 0.25 \mathrm{c}$ \\
\hline SOD & $8.5 \pm 0.58 b$ & $9.9 \pm 0.64 \mathrm{a}$ & $5.4 \pm 0.44 d$ & $6.9 \pm 0.58 c$ \\
\hline CAT & $62.9 \pm 3.57 \mathrm{~b}$ & $71.0 \pm 4.77 \mathrm{a}$ & $40.8 \pm 3.75 \mathrm{~d}$ & $50.8 \pm 3.44 \mathrm{c}$ \\
\hline GST & $0.70 \pm 0.036 b$ & $0.82 \pm 0.041 \mathrm{a}$ & $0.41 \pm 0.034 \mathrm{~d}$ & $0.57 \pm 0.027 \mathrm{c}$ \\
\hline GPx & $33.8 \pm 1.87 \mathrm{~b}$ & $41.9 \pm 2.12 \mathrm{a}$ & $17.8 \pm 0.98 \mathrm{~d}$ & $27.3 \pm 1.40 \mathrm{c}$ \\
\hline TAC & $25.4 \pm 0.80 \mathrm{a}$ & $26.1 \pm 0.76 \mathrm{a}$ & $18.7 \pm 0.32 \mathrm{c}$ & $21.1 \pm 0.24 b$ \\
\hline
\end{tabular}

Mean values within a row not sharing a common superscript letter $(\mathrm{a}, \mathrm{b}, \mathrm{c}, \mathrm{d})$ were significantly different, $p<0.05$

TBARS: Thiobarbituric acid-reactive substances ( $\mathrm{n} \mathrm{mol} / \mathrm{g}$ tissue); NO: Nitric oxide ( $\mu$ mol/g tissue); GSH: Glutathione ( $\mu$ mol/g tissue); SOD: Superoxide dismutase (U/g tissue); CAT: Catalase (U/g tissue); GST: Glutathione S-transferase ( $\mu \mathrm{mol} / \mathrm{h} / \mathrm{g}$ tissue); GPx: Glutathione peroxidase (U/g tissue); TAC: Total antioxidant capacity ( $\mu$ mol/g tissue);

Table 3. Heart free radicals, nitric oxide and antioxidant enzymes of male rats treated with grape seed proanthocyanidin extract (GSPE), thalidomide, carboplatin and their combination (Mean values $\pm \mathrm{SE}$ )

\begin{tabular}{|c|c|c|c|c|}
\hline \multirow{2}{*}{ Parameter } & \multicolumn{3}{|c|}{ Experimental groups } \\
\cline { 2 - 4 } & Control & GSPE & Thalidomide + Carboplatin & Thalidomide + Carboplatin + GSPE \\
\hline TBARS & $20.5 \pm 1.73 \mathrm{c}$ & $17.3 \pm 0.94 \mathrm{~d}$ & $32.0 \pm 2.42 \mathrm{a}$ \\
\hline NO & $0.14 \pm 0.03 \mathrm{c}$ & $0.06 \pm 0.01 \mathrm{~d}$ & $0.28 \pm 0.02 \mathrm{a}$ \\
\hline GSH & $5.8 \pm 0.30 \mathrm{~b}$ & $7.0 \pm 0.52 \mathrm{a}$ & $4.3 \pm 0.21 \mathrm{c}$ \\
\hline SOD & $6.5 \pm 0.22 \mathrm{~b}$ & $8.2 \pm 0.29 \mathrm{a}$ & $4.8 \pm 0.20 \mathrm{c}$ \\
\hline CAT & $61.2 \pm 4.80 \mathrm{~b}$ & $80.2 \pm 2.69 \mathrm{a}$ & $42.5 \pm 2.80 \mathrm{~d}$ \\
\hline GST & $0.77 \pm 0.032 \mathrm{~b}$ & $0.86 \pm 0.018 \mathrm{a}$ & $0.4 \pm \pm 0.014 \mathrm{~d}$ \\
\hline TAC & $33.8 \pm 1.9 \mathrm{~b}$ & $42.7 \pm 2.5 \mathrm{a}$ & $0.12 \mathrm{~b}$ & $0.60 \pm 0.031 \mathrm{c}$ \\
\hline
\end{tabular}

Mean values within a row not sharing a common superscript letter ( $\mathrm{a}, \mathrm{b}, \mathrm{c}, \mathrm{d}$ ) were significantly different, $p<0.05$. TBARS: Thiobarbituric acid-reactive substances (n mol/g tissue); NO: Nitric oxide ( $\mu \mathrm{mol} / \mathrm{g}$ tissue); GSH: Glutathione ( $\mu \mathrm{mol} / \mathrm{g}$ tissue); SOD: Superoxide dismutase (U/g tissue); CAT: Catalase (U/g tissue); GST: Glutathione S-transferase ( $\mu$ mol/h/g tissue); GPx: Glutathione peroxidase (U/g tissue); TAC: Total antioxidant capacity ( $\mu \mathrm{mol} / \mathrm{g}$ tissue); 
Yousef MI (2019) The potential protective role of grape seed proanthocyanidin extract against the mixture of carboplatin and thalidomide -induced hepatotoxicity and cardiotoxicity in male rats

Table 4. Heart paroxanase (PON1) and plasma aspartate aminotransferase (AST), alanine aminotransferase (ALT), acid phosphatase (ACP), alkaline phosphatase (ALP), total protein and albumin of male rats treated with grape seed proanthocyanidin extract (GSPE), thalidomide, carboplatin and their combination (Mean values \pm SE)

\begin{tabular}{|c|c|c|c|c|}
\hline \multirow{2}{*}{ Parameters } & \multicolumn{3}{|c|}{ Experimental groups } \\
\cline { 2 - 4 } & Control & GSPE & Thalidomide+ Carboplatin & Thalidomide+Carboplatin + GSPE \\
\hline PON1(ng/mg protein) & $291 \pm 7.3 \mathrm{~b}$ & $337 \pm 12.8 \mathrm{a}$ & $78 \pm 4.0 \mathrm{~d}$ \\
\hline AST (U/L) & $23.7 \pm 1.61 \mathrm{c}$ & $21.9 \pm 1.99 \mathrm{~d}$ & $42.0 \pm 2.11 \mathrm{a}$ \\
\hline ALT (U/L) & $22.9 \pm 1.84 \mathrm{c}$ & $20.7 \pm 1.26 \mathrm{~d}$ & $33.5 \pm 2.26 \mathrm{a}$ \\
\hline ACP (U/L) & $6.6 \pm 0.36 \mathrm{c}$ & $6.7 \pm 0.34 \mathrm{c}$ & $19.7 \pm 1.41 \mathrm{~b}$ \\
\hline ALP (U/L) & $56.2 \pm 3.5 \mathrm{c}$ & $53.7 \pm 3.3 \mathrm{~d}$ & $7.6 \pm 1.72 \mathrm{a}$ \\
\hline Total protein $(\mathrm{mg} / \mathrm{dl})$ & $6.3 \pm 0.16 \mathrm{a}$ & $6.0 \pm 0.25 \mathrm{a}$ & $95.0 \pm 4.8 \mathrm{a}$ \\
\hline Albumin $(\mathrm{mg} / \mathrm{dl})$ & $4.3 \pm 0.27 \mathrm{a}$ & $4.4 \pm 0.19 \mathrm{a}$ & $4.5 \pm 0.19 \mathrm{c}$ \\
\hline
\end{tabular}

Mean values within a row not sharing a common superscript letter $(\mathrm{a}, \mathrm{b}, \mathrm{c}, \mathrm{d})$ were significantly different, $p<0.05$.

Simultaneously, treatment with GSPE alone significantly $(p>0.05)$ increased the level of PON1 in the heart compared to the control group as shown.

Treatment with thalidomide followed by carboplatin significantly $(p>0.05)$ increase the levels of AST, ALT, ACP, and ALP while significantly $(p>0.05)$ decreased the levels of total protein and albumin compared with the control group. The combination of GSPE with thalidomide and carboplatin significantly $(p>0.05)$ decreased the levels of AST, ALT, ACP, and ALP while significantly $(p>0.05)$ increase in the concentration of total protein and albumin compared to thalidomide and carboplatin group. While, treatment with GSPE significantly $(p>0.05)$ decreased the levels of AST, ALT and ALP and insignificant $(p>0.05)$ increase in ACP level and albumin concentration also, insignificant $(p>0.05)$ decrease in total protein concentration compared with the control group.

\section{Histopathological changes in liver and heart}

\section{Liver histopathological observations}

Microscopic examination of liver sections of thalidomide and carboplatin-treated group showed histopathological alterations; dilation and congestion in the portal vein and sinusoids, loss of the normal hepatocytes architecture, degenerated hepatocytes, hepatocyte vacuolization also, presence of inflammatory cells infiltrations around the portal area (Figure $1 \mathrm{C} 1 \& \mathrm{C} 2$ ), compared to control. On the other hand, the histopathological alterations were noticeably reduced in thalidomide, carboplatin plus GSPE (Figure 1D) compared to thalidomide and carboplatin-treated group. However, sections of control and Grape Seed Proanthocyanidin Extract (GSPE) groups (Figure $1 \mathrm{~A} \& \mathrm{~B}$ ) depicted normal hepatocellular architecture with narrow sinusoidal spaces and a central vein.

\section{Heart histopathological observations}

Histological examination of tissue sections from the heart muscle in thalidomide and carboplatin-treated group (Figure 2C) showed loss of normal architecture of cardiac muscle fibers, loss of cross striations and fragmentation of sarcoplasm, cytoplasmic vacuolization in cardiac muscle cells, edema in connective tissue and congestion between myocardial fibers compared to control. Whereas, heart sections of thalidomide, carboplatin plus GSPE combination group showed less histopathological alterations compared to thalidomide and carboplatintreated group (Figure 2D). Microscopic examination of heart sections of normal control and grape seed proanthocyanidin extract (GSPE) treated groups (Figure $2 \mathrm{~A}$ and $2 \mathrm{~B}$ ) showed normal myofibrillar architecture with adjacent myofibrils.
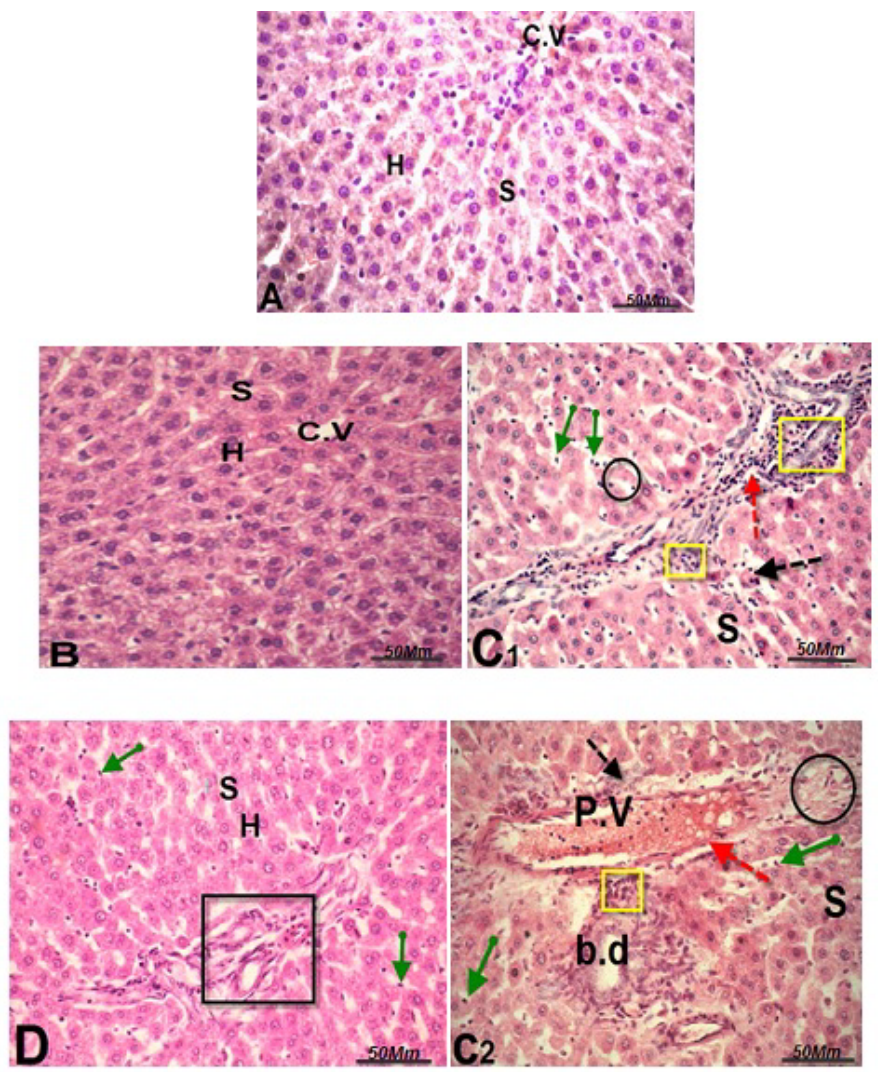

Figure 1. Light micrograph in liver of male rats:

(A) control rats, normal hepatocytes architecture $(\mathrm{H})$, normal blood sinusoids $(\mathrm{S})$ and central vein (C.V).

(B) Section in the liver of rats treated with grape seed proanthocyanidin extract (GSPE), showing normal hepatocytes $(\mathrm{H})$, blood sinusoids $(\mathrm{S})$ and central vein $(\mathrm{C} . \mathrm{V})$

$(\mathrm{C} 1 \& \mathrm{C} 2)$ : sections of thalidomide and carboplatin - treated rats showing, dilatation and hemorrhage in the portal vein (red dotted arrow), lymphocytes aggregation (yellow square), degenerated hepatocytes with pyknotic nuclei (black circle \& black dotted arrows), dilation of blood sinusoids (S) lymphocytes infiltrations around bile duct (b. d) and Kupffer cells (green arrow).

(D) Section in liver of rat treated with thalidomide, carboplatin + GSPE showing slightly improvement of the histological alterations induced by thalidomide and carboplatin treatment with few Kupffer and lymphocytes cells (black square \& green arrow) "H \& E, 400 X"

\section{Discussion}

Administration of carboplatin and thalidomide caused an elevation in liver and heart proinflammatory cytokines; tumor suppressor P53 (P53), tumor necrosis factor- $\alpha$ (TNF- $\alpha$ ) and interleukin-6 (IL-6). These results are in agreement with the report of Rehman et al. [22] and ElAwady et al. [23]. Over production of COX-2 and p53 in Cisplatin 
Yousef MI (2019) The potential protective role of grape seed proanthocyanidin extract against the mixture of carboplatin and thalidomide -induced hepatotoxicity and cardiotoxicity in male rats
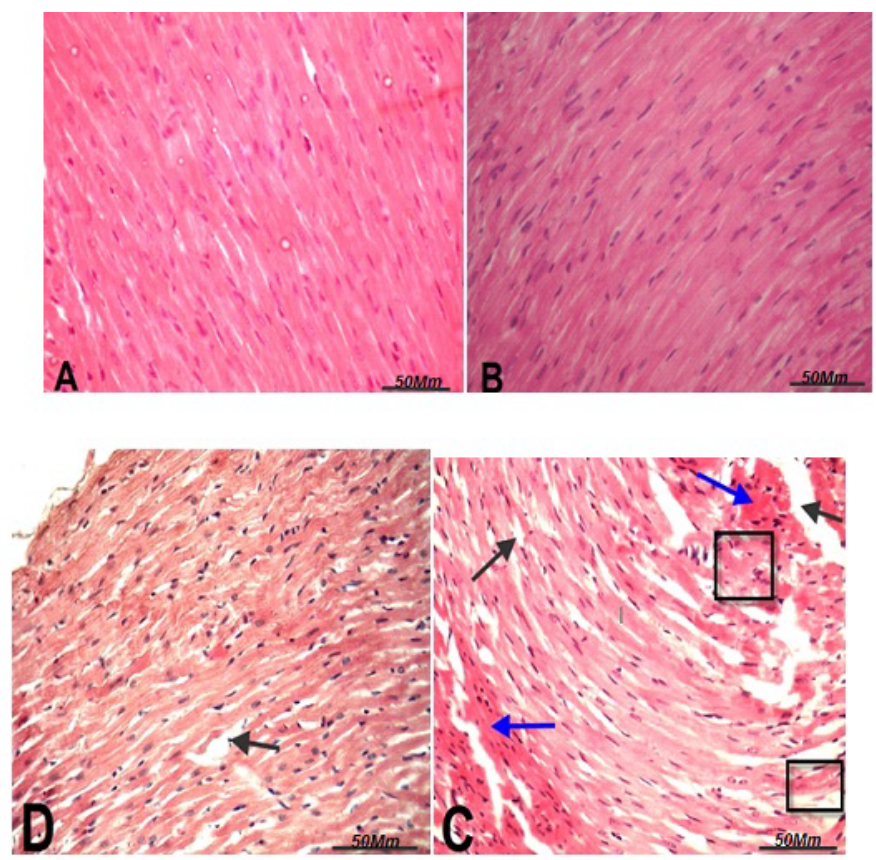

Figure 2. Light micrograph of the heart tissue of rats treated as follow:

(A) Control group

(B) grape seed proanthocyanidin extract (GSPE) -treated group showing normal myofibrillar architecture with striations, branched appearance and continuity with adjacen myofibrils and oval nuclei.

(C) Section in heart tissues of thalidomide and carboplatin -treated group showing loss of normal architecture, disorganization and degeneration in myocardial fibers with pyknotic nuclei (black square), congestion between myocardial fibers (blue arrow), vacuoles (black arrow). Histological alterations induced by thalidomide and carboplatin treatment were slightly reduced in the combination group

(D) thalidomide and carboplatin + GSPE -treated rats. (H. \& E, X 400).

-injured tissue might be related to Cisplatin-induced inflammation and apoptosis, respectively. So, inflammation plays an important role in the pathogenesis of tissue damage induced by Cisplatin. Besides, p53 plays a critical role in the cellular apoptotic pathway leading from Cisplatin -DNA crosslinking to caspase-3 activation [24]. In addition, DNA damage leads to phosphorylation of p53 in the liver [25]. Also, in the present study, the enhancement in the TNF- $\alpha$ and IL- 6 cytokine levels may be due to treatment with carboplatin and thalidomide. These results are similar [3]. This elevation in the proinflammatory cytokines also came in the same line with the reports of Kim et al. [26] who suggested that cisplatin-induced activation of proinflammatory cytokines and NF-kB directly involves c-jun $\mathrm{N}$-terminal kinase and mitogen-activated protein kinases/ extracellular signal-regulated kinase (JNK and MEK/ERK) signaling pathways. TNF- $\alpha$ was identified as an endogenous pyrogen and a key component of an inflammatory response and one of the most potent pro-inflammatory cytokines released by innate immune cells [27]. As well as, IL- 6 is secreted by the white blood cells, such as macrophages and endothelial cells and any inflammatory stimulus can increase the IL-6 concentrations [27].

However, grape seed proanthocyanidin extract modulated the values of various inflammatory cytokines; P53, TNF- $\alpha$ and IL6 near to normal values. This may be attributed to the anti-inflammatory role of GSPE [28]. They added, GSPE supplementation caused an elevation in the Nrf2 expression led to modulation in antioxidant enzymes.

In the present study, carboplatin and thalidomide administration increased the level of TBARS, NO and decreased the level of GSH and
TAC, as well as decline the activities of antioxidant enzymes SOD, CAT, GST and GPX in the liver and heart of male rats. These results are in the same line with those of El-Kholy et al. [29] who indicated that cisplatin increased oxidative stress, the level of malondialdehyde (MDA) accompanied with decline in reduced glutathione (GSH), antioxidant enzymes activities as superoxide dismutase (SOD) and catalase (CAT). This may be attributed to cisplatin inhibit the defense of anti-oxidative system and induce liver oxidative stress injury. Also, Bahadir et al. [30] reported that the increases in the levels of MDA designate the myocardial damage with a decline in the GSH level and SOD, CAT activities in the Cisplatin -treated rats. This may be due to Cisplatin-induced cardiotoxicity, increased activity of reactive oxygen species caused an elevation in MDA production.

Nannelli et al. [31] mentioned that a reduction in glutathione levels accompanied by an alteration in the cellular redox state occurred by carboplatin. This leads to a reduction in performance of the antioxidant enzyme defense system.

Furthermore, the elevation in the levels of TBARS, nitric oxide and proinflammatory cytokines in the thalidomide and carboplatintreated group, as well as the depletion in the levels of glutathione (GST). These results are concomitant with the increases in IL-6. These may be regarded as the reduction in intracellular GSH, which has been coupled with increasing cytokine biosynthesis, including the release of IL-6 [32]. The mechanism implicated a ROS-sensitive pathway since the depletion of GSH strengthened IL- 6 release and the production of free radicals. Additionally, ROS-mediated activation of NF-kB can lead to upregulation of cytokine expression [33].

However, administration of GSPE caused a reduction in oxidative stress markers elevated the antioxidant enzymes activities against hepatic and cardiac damage. This may be due to GSPE increased Nrf2 nuclear translocation to promote the Nrf2 signaling pathway, thus enhancing antioxidant defense systems during hepatotoxicity [34].

In addition, Proanthocyanidins contain a large amount of $\mathrm{H}+$, which can block free radical chain reaction, thus improving the activity of various antioxidant enzymes and antioxidant substances in cells [35]. GSPE considered as antioxidant, antiinflammation and antiatherosclerosis [36,37]. Also, Puiggròs et al. [38] reported that procyanidins elicit the upregulation of a sequence of antioxidant and detoxification enzymes that enhance cellular defenses.

In the current data, administration of carboplatin and thalidomide revealed elevation in PON1, ALT, AST, ACP, ALP activities, also reduction in total protein and albumin content.

Similarly, Iseri et al. [39] indicated a significant disorder in the activities of plasma AST and ALT through treatment with platinum compounds. The alterations in the activity of these enzymes could be a secondary event following platinum-induced liver damage with the subsequent leakage from hepatocytes. Yilmaz et al., [40] reported that the involvement of oxidative stress, lipid peroxidation and mitochondria dysfunction in CDDP -induced liver toxicity. They added, oxidative stress is a common pathogenetic mechanism contributing to the initiation and progression of hepatic damage in a variety of liver disorders.

Transaminases are the most sensitive biomarkers directly implicated in the extent of cellular damage and toxicity because they are cytoplasmic in location and are released into the circulation after cellular damage [41]. Moreover, Rehman et al. [22] indicated that alterations in AST and ALT are reported in hepatic disease and in myocardial infarction. 
Yousef MI (2019) The potential protective role of grape seed proanthocyanidin extract against the mixture of carboplatin and thalidomide -induced hepatotoxicity and cardiotoxicity in male rats

In the current data, the reduction in total protein and albumin may be attributed to the chemotherapeutic agents caused alterations in protein, albumin and liver enzymes and this may be due to the injured kidney [42]. In addition, platinum drugs diminish DNA, RNA and protein synthesis. The inhibition of protein synthesis associated with platinum compounds may be attributed to platinum-induced transcription high jacking. So, transcription high jacking refers to the consequences of the ability of certain transcription factors to join DNA adducts caused by organ platinum compounds [43].

In addition, augmented protein metabolism, albuminuria, and microproteinuria may attribute to the reduction in serum levels of total protein and albumin. Also, high production of urea may be a result of increased proteins catabolism in the liver and plasma [44].

The presence of GSPE with carboplatin and thalidomide minimized their toxic effect on PON1, ALT, AST, ACP, ALP activities, also modulated total protein and albumin content to reach near to the control values. These results are consistent with the findings of Karthikeyan et al. [45] reported that administration of GSPE maintained the levels of the marker enzymes (AST, ALT, LDH, and CK). The maintenance of the levels of marker enzymes may be due to the free radical scavenging property of anti-oxidative phytochemicals such as flavonoids present in GSPE. A possible explanation for this is that GSPE, via its antilipid peroxidation activity, causes stabilization of cardiac membranes and prevents the leakage of cardiac enzymes. Moreover, the main polyphenol components in GSPE are (+)-catechin (C), (-)-epicatechin (EC), (-)-epicatechin gallate (ECG) and proanthocyanidin dimer B2 (EC-EC). Also, Phenolic antioxidants reduce lipid peroxidation through a rapid donation of a hydrogen atom to the peroxyl radical (ROO) resultant in the creation of alkyl (aryl) hydroperoxide (ROOH). The polyphenol phenoxy radical formed can be stabilized by further donation of a hydrogen atom [46].

Administration of GSPE mitigated $\mathrm{H}_{2} \mathrm{O}_{2}$-induced oxidant stress in cardiomyocytes. This action is coupled with an increase in cardiomyocyte survival. So, the cardioprotective effects of GSPE could be realized by reduction or removal of free radicals in the myocardium [47]. Likewise, Issabeagloo et al. [48] reported that GSPE treatment improves hepatic status. This attributed to cellular regeneration and stability of cell membrane which in turn, exclude the penetration of intracellular enzymes.

The biochemical parameters are confirmed by histopathological results which showed, loss of the normal hepatocytes architecture, degenerated hepatocytes with vacuolization as well as, dilation and congestion in the portal vein and sinusoids. Moreover, distortion and degeneration in myocardial fibers with pyknotic nuclei in carboplatin thalidomide group.

These results agreed with Kart et al. [49] who reported that cisplatininduced hepatic damage manifested by pericentral disorganization, hepatic necrosis, and apoptotic changes.

It was shown that cisplatin induces liver cells apoptosis by cytochrome-c release and caspase 3 release activation. Also, hepatotoxicity occurs by increasing messenger Ribonucleic Acid (mRNA) expression of nuclear factor-kappa B (NF-kb) dependent Cyclo-Oxygenase (COX-II) and inducible nitric oxide synthase (iNOS) [50].

In addition, the cardiac impairment produced after cisplatin administration revealed degeneration and necrosis of cardiac muscle fiber cells [51]. Also, cisplatin treatment may lead to degenerative changes in cardiac tissues, which may point to the possible consideration of carnitine deficiency. This result is supported by Zahkouk et al. [52] who reported that cardiac tissue damage may be due to the elevation in the lipid peroxidation (MDA) and reduction in GSH and CAT levels.

The current data revealed that GSPE ameliorated the histological changes in liver and heart motivated by carboplatin and thalidomide. In general, these results were consistent with those of Kandemir et al. [53]. They reported that co-treatment with GSPE has been relieved hepatotoxicity since; histopathological changes were noteworthy less pronounced compared to animals treated with cisplatin alone. Supplementation of GSPE exhibited normal organization of the cardiac muscle fibers. The present results were in the same line with the results of Lian et al. [54] who reported the protective role of GSPE against cisplatin-induced cardiac toxicity and histological alteration in heart tissue of rats.

\section{Conclusion}

In spite of the efficacy of carboplatin and thalidomide treatment, there is a restriction for their use in order to their negative effects on most of the tissue functions. GSPE acts as a potent natural antioxidant due to its antioxidant properties; GSPE exhibited a protective effect on liver and heart tissues against carboplatin and thalidomide -induced damage in rats. It could improve the proinflammatory status in liver and heart. It also attenuated the lipid peroxidation, nonenzymatic and enzymatic antioxidants also, liver and heart functions near to the control values. The biochemical analysis confirmed by histopathological investigations. So, the present work indicates that GSPE has a promising therapeutic role as a preventive agent against hepatotoxicity and cardiotoxicity motivated by carboplatin and thalidomide.

\section{Acknowledgement}

This research is funded by a private partnership. Also, the research received no specific funding from any agency in the public, commercial.

\section{References}

1. Palencia G, Núñez-Medrano JÁ, Ortiz-Plata A, Farfán DJ, Sotelo J, et al. (2015) Anti-apoptotic, antioxidant, and anti-inflammatory effects of thalidomide on cerebral ischemia/reperfusion injury in rats. J Neurol Sci 351: 78-87. [Crossref]

2. Liu T, Guo F, Zhu X, He X, Xie L (2017) Thalidomide and its analogues: A review of the potential for immunomodulation of fibrosis diseases and opthalmopathy. Exp Ther Med 14: 5251-5257. [Crossref]

3. Yousef MI, Khalil DK, Abdou HM (2018) Neuro-and nephroprotective effect of grape seed proanthocyanidin extract against carboplatin and thalidomide through modulation of inflammation, tumor suppressor protein $\mathrm{p} 53$, neurotransmitters, oxidative stress and histology. Toxicol Rep 5: 568-578. [Crossref]

4. Teo S, Resztak KE, Scheffler MA, Kook KA, Zeldis JB, et al. (2002) Thalidomide in the treatment of leprosy. Microbes Infect 4: 1193-1202. [Crossref]

5. Wheate NJ, Walker S, Craig GE, Oun R (2010) The status of platinum anticancer drugs in the clinic and in clinical trials. Dalton Trans 39: 8113-812. [Crossref]

6. Organization WH (2013) Who model list of essential medicines: $18^{\text {th }}$ list, April 2013.

7. Yousef M, Saad A, El-Shennawy L (2009) Protective effect of grape seed proanthocyanidin extract against oxidative stress induced by cisplatin in rats. Food Chem Toxicol 47: 1176-1183. [Crossref]

8. Conklin KA (2004) Chemotherapy-associated oxidative stress: Impact on chemotherapeutic effectiveness. Integr Cancer Ther 3: 294-300. [Crossref]

9. Dintcheva NT, Arrigo R, Baiamonte M, Rizzarelli P, Curcuruto G (2017) Concentrationdependent anti-/pro-oxidant activity of natural phenolic compounds in bio-polyesters. Polym Degrad Stab 142: 21-28.

10. Zhang HM, Zhang Y (2014) Melatonin: a well-documented antioxidant with conditional pro-oxidant actions. J Pineal Res 57: 131-146. [Crossref] 
Yousef MI (2019) The potential protective role of grape seed proanthocyanidin extract against the mixture of carboplatin and thalidomide -induced hepatotoxicity and cardiotoxicity in male rats

11. Bahramsoltani R, Rahimi R, Farzaei MH (2017) Pharmacokinetic interactions of curcuminoids with conventional drugs: A review. J Ethnopharmacol 209: 1-12. [Crossref]

12. Hassan HA, Al-Rawi MM (2013) Grape seeds proanthocyanidin extract as a hepaticreno-protective agent against gibberellic acid induced oxidative stress and cellular alterations. Cytotechnology 65: 567-576. [Crossref]

13. Kaczmarczyk-Sedlak I, Zych M, Rotko K, Sedlak L (2012) Effects of thalidomide on the development of bone damage caused by prednisolone in rats. Pharmacol Rep 64: 386-395. [Crossref]

14. Husain K, Scott R, Whitworth C, Somani S, Rybak L (2001) Dose response of carboplatin-induced hearing loss in rats: Antioxidant defense system. Hear Res 151: 71-78. [Crossref]

15. Curiale MS, Klatt MJ, Gehle WD, Chandonnet HE (1990) Colorimetric and fluorometric substrate immunoassays for detection of Salmonella in all foods: comparative study. $J$ Assoc Off Anal Chem 73: 961-968. [Crossref]

16. Yang A, Kaghad M, Caput D, McKeon F (2002) On the shoulders of giants: p63, p73 and the rise of p53. Trends Genet 18: 90-95. [Crossref]

17. Hedayati M, Yazdanparast R, Azizi F (2001) Determination of human tumor necrosis factor a by a highly sensitive enzyme immunoassay. Biochem Biophys Res Commun 289: 295-298. [Crossref]

18. Ferguson-Smith AC, Chen Y-F, Newman MS, May LT, Sehgal PB et al. (1988) Regional localization of the interferon- $\beta 2 \mathrm{~b}$-cell stimulatory factor 2 /hepatocyte stimulating factor gene to human chromosome 7p15-p21. Genomics 2: 203-208. [Crossref]

19. Carleton HM, Drury RAB, Wallington EA (1980) Carleton's histological technique. Oxford University Press, USA.

20. Institute SAS (1999) Sas/stat user's guide, version 8. SAS Institute.

21. Pratibha R, Sameer R, Rataboli PV, Bhiwgade DA, Dhume CY (2006) Enzymatic studies of cisplatin induced oxidative stress in hepatic tissue of rats. Eur J Pharmacol 532: 290-293. [Crossref]

22. Rehman MU, Ali N, Rashid S, Jain T, Nafees S, et al. (2014) Alleviation of hepatic injury by chrysin in cisplatin administered rats: Probable role of oxidative and inflammatory markers. Pharmacol Rep 66: 1050-1059. [Crossref]

23. El-Awady E-SE, Moustafa YM, Abo-Elmatty DM, Radwan A (2011) Cisplatin-induced cardiotoxicity: Mechanisms and cardioprotective strategies. Eur J Pharmacol 650: 335-341. [Crossref]

24. Martins N, Santos NAGd, Curti C, Bianchi MdLP, Santos ACd (2008) Cisplatin induces mitochondrial oxidative stress with resultant energetic metabolism impairment, membrane rigidification and apoptosis in rat liver. J Appl Toxicol 28: 337-344. [Crossref]

25. Narayana K (2012) Effects of 1-ascorbic acid on two cycles of cisplatin-induced DNA double-strand breaks and phosphorylation of 553 in the liver. Exp Toxicol Pathol 64: 495-502.

26. Kim HJ, So HS, Lee JH, Park C, Lee JB, et al. (2008) Role of proinflammatory cytokines in cisplatin-induced vestibular hair cell damage. Head Neck 30: 1445-1456 [Crossref]

27. Bacci M, Leme R, Zing N, Murad N, Adami F, et al. (2015) Il-6 and TNF-a serum levels are associated with early death in community-acquired pneumonia patients. Braz J Med Biol Res 48: 427-432. [Crossref]

28. Liu W, Xu C, Sun X, Kuang H, Kuang X, et al. (2016) Grape seed proanthocyanidin extract protects against perfluorooctanoic acid-induced hepatotoxicity by attenuating inflammatory response, oxidative stress and apoptosis in mice. Toxicol Res 5: 224-234. [Crossref]

29. El-Kholy AA, Elkablawy MA, El-Agamy DS (2017) Lutein mitigates cyclophosphamide induced lung and liver injury via nf-?b/mapk dependent mechanism. Biomed Pharmacother 92: 519-527. [Crossref]

30. Bahadir A, Ceyhan A, Gergin ÖÖ, Yalçin B, Ülger M, et al. (2018) Protective effects of curcumin and beta-carotene on cisplatin-induced cardiotoxicity: An experimental rat model. Anatol J Cardiol 19: 213. [Crossref]

31. Nannelli A, Messina A, Marini S, Trasciatti S, Longo V, et al. (2007) Effects of the anticancer dehydrotarplatin on cytochrome p450 and antioxidant enzymes in male rat tissues. Arch Toxicol 81: 479. [Crossref]

32. Haddad JJ (2000) Glutathione depletion is associated with augmenting a proinflammatory signal: Evidence for an antioxidant/pro-oxidant mechanism regulating cytokines in the alveolar epithelium. Cytokines Cell Mol Ther 6: 177-187. [Crossref]

33. Song M, Kellum JA, Kaldas H, Fink MP (2004) Evidence that glutathione depletion is a mechanism responsible for the anti-inflammatory effects of ethyl pyruvate in cultured lipopolysaccharide-stimulated raw 264.7 cells. J Pharmacol Exp Ther 308: 307-316. [Crossref]
34. Liu B, Jiang H, Lu J, Baiyun R, Li S, et al. (2018) Grape seed procyanidin extract ameliorates lead-induced liver injury via mirna 153 and akt/gsk-3ß/fyn-mediated nrf2 activation. J Nutr Biochem 52: 115-123. [Crossref]

35. Xu M, Niu Q, Hu Y, Feng G, Wang H, et al. (2019) Proanthocyanidins antagonize arsenic-induced oxidative damage and promote arsenic methylation through activation of the nrf2 signalling pathway. Oxid Med Cell Longev 2019: 8549035. [Crossref]

36. Pallarès V, Fernández-Iglesias A, Cedó L, Castell-Auví A, Pinent M, et al. (2013) Grape seed procyanidin extract reduces the endotoxic effects induced by lipopolysaccharide in rats. Free Radic Biol Med 60:107-114. [Crossref]

37. Terra X, Pallarés V, Ardèvol A, Bladé C, Fernández-Larrea J, et al. (2011) Modulatory effect of grape-seed procyanidins on local and systemic inflammation in diet-induced obesity rats. J Nutr Biochem 22: 380-387. [Crossref]

38. Puiggròs F, Llópiz N, Ardévol A, Bladé C, Arola L, et al. (2005) Grape seed procyanidins prevent oxidative injury by modulating the expression of antioxidant enzyme systems. J Agr Food Chem 53: 6080-6086. [Crossref]

39. Iseri S, Ercan F, Gedik N, Yüksel M, Alican I (2007) Simvastatin attenuates cisplatininduced kidney and liver damage in rats. Toxicology 230: 256-264. [Crossref]

40. Yilmaz HR, Iraz M, Sogut S, Ozyurt H, Yildirim Z, et al. (2004) The effects of erdosteine on the activities of some metabolic enzymes during cisplatin-induced nephrotoxicity in rats. Pharmacol Res 50: 287-290. [Crossref]

41. Stockham S, Scott M (2002) Fundamentals of veterinary clinical pathology. Ames Iowa State University Press 52: 434-459.

42. Venkatesan N, Punithavathi D, Arumugam V (2000) Curcumin prevents adriamycin nephrotoxicity in rats. Br J Pharmacol 129: 231-234. [Crossref]

43. Tarloff JB, Lash LH. (2004). Toxicology of the kidney. CRC Press.

44. Kumar G, Banu G, Ganesan Murugesan A, Rajasekara Pandian M (2010) Effect of helicteres isora bark extract on protein metabolism and marker enzymes in streptozotocin-induced diabetic rats. Iran J Pharm Res 147-149.

45. Karthikeyan K, Bai BS, Devaraj SN (2007) Cardioprotective effect of grape seed proanthocyanidins on isoproterenol-induced myocardial injury in rats. Int $J$ Cardiol 115: 326-333. [Crossref]

46. Cadenas E, Packer L (2002) Handbook of antioxidants: Revised and expanded. New York: Marcel Dekker.

47. Bagchi D, Bagchi M, Stohs SJ, Ray SD, Sen CK, et al. (2002) Cellular protection with proanthocyanidins derived from grape seeds. Ann N Y Acad Sci 957: 260-270. [Crossref]

48. Issabeagloo E, Ahmadpoor F, Kermanizadeh P, Taghizadieh M (2012) Hepatoprotective effect of green tea on hepatic injury due to leflunomide in rat. Asian J Exp Biol Sci 3:136-141.

49. Kart A, Cigremis Y, Karaman M, Ozen H (2010) Caffeic acid phenethyl ester (cape) ameliorates cisplatin-induced hepatotoxicity in rabbit. Exp Toxicol Pathol 62: 45-52. [Crossref]

50. Kim SH, Hong KO, Chung W-Y, Hwang JK, Park K-K (2004) Abrogation of cisplatininduced hepatotoxicity in mice by xanthorrhizol is related to its effect on the regulation of gene transcription. Toxicol Appl Pharmacol 196: 346-355. [Crossref]

51. Ismail SH, Attyah AM (2012) Protective effect of ginger extract against cisplatin-induced hepatotoxicity and cardiotoxicity in rats. Iraqi J Pharm Sci 21: 27-33. [Crossref]

52. Zahkouk SA, El-Gendy AM, Eid FA, El-Tahway NA, El-Shamy SA (2015) Physiological and histological studies on the heart of male albino rats exposed to electromagnetic field and the protective role of silymarin and/or vitamin E. Egypt $J$ Hosp Med 31: 1-15.

53. Kandemir F, Benzer E, Ozkaraca M, Ceribasi S, Yildirim NC, et al. (2012) Protective antioxidant effects of grape seed extract in a cisplatin-induced hepatotoxicity model in rabbits. Rev Med Vet-Toulouse 163: 539-545.

54. Lian Y, Gao L, Guo P, Zhao Y, Lin T (2016) Grape seed proanthocyanidins extract prevents cisplatin-induced cardiotoxicity in rats. Food Sci Technol Res 22: 403-408.

Copyright: (C2019 Yousef MI. This is an open-access article distributed under the terms of the Creative Commons Attribution License, which permits unrestricted use, distribution, and reproduction in any medium, provided the original author and source are credited. 